\title{
The Yunnan national medicine Maytenus compound inhibits the proliferation of hepatocellular carcinoma (HCC) by suppressing the activation of the EGFR-PI3K- AKT signaling pathway
}

\author{
Wen-Tao Zhao ${ }^{*}$, Liu-Xin Han² ${ }^{*}$, Lin Liu ${ }^{3 *}$, Bao-Zhen Zeng ${ }^{4}$, Yi Zhang 5 , Liu-Fang Zhao ${ }^{6}$, Hong-Yan Hu ${ }^{7}$,

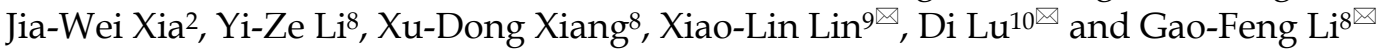 \\ 1. Department of Gastrointestinal Oncology, The Third Affiliated Hospital of Kunming Medical University (Yunnan Cancer Hospital, Yunnan Cancer Center), Kunming \\ 650118, China. \\ 2. The third people's hospital of Kunming (The Sixth Affiliated Hospital of Dali University), Kunming 650041, China. \\ 3. Department of Traditional medicine research laboratory, Puer Traditional Ethnomedicine Institute, Puer 665000, China. \\ 4. Department of Pathology, Guangdong Provincial People's Hospital, Guangdong Academy of Medical Sciences, Guangzhou 510080, China. \\ 5. Department of Gynecology, The Third Affiliated Hospital of Kunming Medical University (Yunnan Cancer Hospital, Yunnan Cancer Center), Kunming 650118, China. \\ 6. Department of Head and Neck Cancer, The Third Affiliated Hospital of Kunming Medical University (Yunnan Cancer Hospital, Yunnan Cancer Center), Kunming \\ 650118, China. \\ 7. Department of Pathology, The Third Affiliated Hospital of Kunming Medical University (Yunnan Cancer Hospital, Yunnan Cancer Center), Kunming 650118, China. \\ 8. Department of Thoracic Surgery, The Third Affiliated Hospital of Kunming Medical University (Yunnan Cancer Hospital, Yunnan Cancer Center), Kunming 650118, \\ China. \\ 9. Guangdong Provincial Key Laboratory of Cancer Immunotherapy Research and Guangzhou Key Laboratory of Tumor Immunology Research, Cancer Research \\ Institute, School of Basic Medical Sciences, Southern Medical University, Guangzhou 510515, China. \\ 10. Technology Transfer Center, Kunming Medical University, Kunming 650500, China. \\ ${ }^{*}$ Co-first authors with equal contributions to this work. \\ $\triangle$ Corresponding authors: Gao-Feng Li, E-mail: ligaofenghl@126.com; Di Lu, E-mail: ludi20040609@126.com; Xiao-Lin Lin, E-mail: 1x10644@smu.edu.cn.
}

(C) The author(s). This is an open access article distributed under the terms of the Creative Commons Attribution License (https://creativecommons.org/licenses/by/4.0/). See http://ivyspring.com/terms for full terms and conditions.

Received: 2020.11.25; Accepted: 2021.03.14; Published: 2021.04.07

\begin{abstract}
Objective: To investigate the effects of Maytenus compound on the proliferation of hepatocellular carcinoma (HCC) cells in vitro and in vivo and to explore the underlying mechanism.

Methods: The half maximal inhibitory concentration (IC50) values of Maytenus compound in HepG2 and BEL-7402 cells were determined by the MTS assay. HepG2 and BEL-7402 cells were treated with different concentrations of Maytenus compound. MTS assay, colony formation assay and cell cycle analysis were performed to clarify the inhibitory effect of Maytenus compound on the proliferation of HepG2 and BEL-7402 cells in vitro. After subcutaneous injection of HepG2 cells, nude mice were randomly divided into a vehicle control group and a drug intervention group, which were intragastrically administered $\mathrm{ddH}_{2} \mathrm{O}$ or Maytenus compound, respectively. The inhibitory effect of Maytenus compound on the proliferation of HepG2 cells in vivo was analyzed using subcutaneous tumor growth curves, tumor weight, the tumor growth inhibition rate and the immunohistochemical detection of BrdU-labeled cells in $S$ phase. The organ toxicity of Maytenus compound was initially evaluated by comparing the weight difference and organ index of the two groups of nude mice. The main proteins in the EGFR-PI3K-AKT signaling pathway were detected by Western blot after Maytenus compound intervention in vivo and in vitro.

Results: Maytenus compound showed favorable antiproliferation activity against HepG2 and BEL-7402 cells with IC50 values of $79.42 \pm 11.71 \mu \mathrm{g} / \mathrm{mL}$ and $78.48 \pm 8.87 \mu \mathrm{g} / \mathrm{mL}$, respectively. MTS assay, colony formation assay and cell cycle analysis showed that Maytenus compound at different concentration gradients within the IC50 concentration range significantly suppressed the proliferation of HepG2 and BEL-7402 cells in vitro and inhibited cell cycle progression from G1 to S phase. Additionally, Maytenus compound, at an oral dose of $2.45 \mathrm{~g} / \mathrm{kg}$, dramatically inhibited, without obvious organ toxicity, the proliferation of subcutaneous tumors formed by HepG2 cells in nude mice. In addition, the tumor growth inhibition rate for Maytenus compound was $66.94 \%$. Furthermore, Maytenus compound inhibited the
\end{abstract}


proliferation of liver orthotopic transplantation tumors in nude mice. Western blot analysis showed that Maytenus compound significantly downregulated the expression of $\mathrm{p}$-EGFR, $\mathrm{p}-\mathrm{PI} 3 \mathrm{~K}$, and $\mathrm{p}-\mathrm{AKT}$ and upregulated the expression of p-FOXO3a, p27, and p21 in vivo and in vitro.

Conclusion: Maytenus compound significantly inhibited the proliferation of HCC cells in vitro and in vivo. The downregulation of the EGFR-PI3K-AKT signaling pathway and subsequent inhibition of cell cycle progression from Gl to $S$ phase is one of the possible mechanisms. Maytenus compound has a high tumor growth inhibition rate and has no obvious organ toxicity, which may make it a potential anti-HCC drug, but the results from this study need to be confirmed by further clinical trials in HCC patients.

Key words: Maytenus compound, Hepatocellular Carcinoma (HCC), EGFR-PI3K-AKT signaling pathway, Proliferation

\section{Introduction}

Primary hepatocellular carcinoma (HCC) has an insidious onset and a high degree of malignancy. It is difficult to diagnose at the early stage, and patient prognosis is poor. HCC is among the malignant tumors with the highest morbidity and mortality rates in the world [1]. Surgery and liver transplantation are the major treatment methods for HCC. However, $70 \%-80 \%$ of patients are at an advanced stage at the time of diagnosis [2]. Surgery and liver transplantation are only suitable for $15 \%$ of HCC patients [3]. Currently, the average five-year survival rate for HCC patients is less than 10\% [4]. Drugs for the systemic treatment for late-stage HCC are limited, and HCC is extremely insensitive to traditional chemotherapy drugs; thus far, there is no standard drug treatment or regimen [5]. Sorafenib is a clinically recognized and effective therapeutic drug that targets HCC, and immunotherapy drugs, which have recently become a research focus, have also shown efficacy in HCC treatment to a certain extent. However, HCC can rapidly acquire drug resistance to sorafenib [6]. Furthermore, clinical trial showed that the objective response rate (ORR) of sorafenib in the patients with HCC was only $2 \%$ to $3 \%$ [7]. Thus, the survival of patients with advanced HCC is only prolonged by 2.8 months [8]. Immunotherapeutic drugs are expensive, and clinical studies have shown that compared with placebo, the programmed death receptor-1 (PD-1) inhibitor pembrolizumab only prolongs the survival of HCC patients by 3 months [9]. Therefore, the current treatment status of HCC is not optimistic, and the lack of effective therapeutic drugs is a substantial clinical challenge. Therefore, it is important to find new and effective drugs for HCC.

Maytenus compound is an innovative novel drug selected and developed from folk traditional medicine used by Lahu people in Yunnan Province, China, by the Pu'er Nationality Research Institute of Traditional Medicine in the process of exploring traditional Chinese medicine, and this drug has been granted a Chinese invention patent (patent number: ZL200710066377.7). Maytenus compound has been utilized for more than 500 years, and it has been included in Chinese Lahu Nationality Medicine and Selection of Lahu's Folk Traditional Medicine. Maytenus compound tablets consist of six herbal medicines, including Maytenus hookeri Loes, Oldenlandia Diffusa Willd, Balanophora Harlandii Hook.f, and Glycyrrhiza uralensis Fisch, and are prepared using aqueous extraction (sugar-coated tablet). As early as 2005, Maytenus compound was approved by the Yunnan Food and Drug Administration as a hospital formulation for clinical application (approval No: (Z) 05J02424). Maytenus compound tablets can be used for the clinical treatment of uterine fibroids and mammary gland hyperplasia, with efficacy rates as high as $90 \%$ and $98 \%$, respectively, and few side effects [10]. In the records of empirical prescriptions by the Lahu people, there is evidence of using Maytenus compound for the treatment of HCC. There is also a small sample single-center clinical observation study of Maytenus compound for the treatment of HCC in China. The study indicated that alpha-fetoprotein (AFP), a specific tumor marker, was significantly decreased in HCC patients after Maytenus compound treatment. Maytenus compound has an important role in improving the quality of life of HCC patients, but the underlying mechanism has not been elucidated [11]. In our study, compared to Maytenus compound used in the aforementioned clinical studies, the drug used in our study had the same sovereign drug (Maytenus) but had the different compatible drugs, and the proportion of each component was different. The drug used in our study was easy to manufacture and inexpensive and could become a new drug candidate with potential research and development (R\&D) and application prospects for HCC treatment. This study clarified the significant inhibitory effect of Maytenus compound on the proliferation of HCC cells both in vitro and in vivo and explored the possible mechanism of action to provide a theoretical basis for the application of Maytenus compound for the treatment of HCC in clinical practice. 


\section{Materials and Methods}

\section{Preparation of Maytenus compound}

Per gram Maytenus compound tablet [(Z05J02424), Puer Traditional Ethnomedicine Institute, China] included Maytenus $235 \mathrm{mg}$, Sargrassum $176.5 \mathrm{mg}$, Oldenlandia Diffusa Willd $176.5 \mathrm{mg}$, Balanophora Harlandii Hook.f., $176.5 \mathrm{mg}$, Tripterygium Hypoglaucum Hutch $176.5 \mathrm{mg}$, and Paris Polyphylla $59 \mathrm{mg}$. The tablets were grinded into powder and dissolved in Dimethyl Sulfoxide (DMSO; D2650, Sigma, USA) for further tests. And the control is $0 \mu \mathrm{g} / \mathrm{mL}$ of Mytenus, which medium add with Dymethyl sulfoxide [12].

\section{Cell lines and cell culture}

The human HCC cell lines HepG2 and BEL-7402 were purchased from the Cell Bank of the Chinese Academy of Sciences (Shanghai, China). The cells were cultured with Dulbecco's modified Eagle's medium (DMEM) (high glucose) containing 10\% fetal bovine serum (FBS) in a humidified incubator with $5 \% \mathrm{CO}_{2}$ at $37{ }^{\circ} \mathrm{C}$. The Maytenus compound tablets were grinded into powder and dissolved in Dimethyl Sulfoxide (DMSO) before it was used to treat HCC cells.

\section{Determination of IC50}

The experimental protocol was performed as described previously [12]. Briefly, the HCC cells were seeded into 96-well culture plates $\left(3 \times 10^{3} /\right.$ well $)$; each group had six duplicate wells. After the cells were cultured for $24 \mathrm{~h}$, they were treated with different doses $(0,2.34375,4.6875,9.375,18.75,37.5,75,150,300$, 600,1200 and $2400 \mu \mathrm{g} / \mathrm{mL}$ ) of Maytenus compound for $72 \mathrm{~h}$. Then, $30 \mu \mathrm{L}$ of MTS (G111A, Promega, USA) was added to each well, and the cells were further incubated for $2 \mathrm{~h}$. Absorbance of each sample was measured using a full wavelength scanner (Varioskan Flash, Thermo Fisher, USA) at $490 \mathrm{~nm}$. IC50 is the concentration that is required to inhibit $50 \%$ of cell growth. The Bliss method was used to calculate the IC50 from survival curves [13].

\section{MTS assay and colony formation assay}

For the MTS assay, the indicated cells were seeded in 96-well plates at $1 \times 10^{3}$ per well in a final volume of $200 \mu \mathrm{l}$ of complete medium with different concentrations of Maytenus compound. For the colony formation assay, the cells were counted and seeded (200 cells/per well) in 6-well plates with complete medium for $24 \mathrm{~h}$. Then, cells were treated with different concentrations of Maytenus compound for $72 \mathrm{~h}$. Finally, cells were incubated continuously without the drug effect for 14 days.

\section{Cell cycle analysis}

For the cell cycle analysis, HCC cells were seeded in 6-well plates $\left(2 \times 10^{5}\right.$ per well $)$ and cultured in complete medium in an incubator for $8 \mathrm{~h}$. Then, the cells were cultured in complete medium with different concentrations of Maytenus compound for $24 \mathrm{~h}$. The remaining experimental protocol was performed as described previously [14].

\section{In vivo antitumor tests}

Female BALB/c nude mice (4-5 weeks old) were purchased from the Charles River Laboratory Animal Technology Inc., Beijing. HepG2 cells $\left(2 \times 10^{6}\right.$ cells $)$ were subcutaneously injected into the right armpit of nude mice $(n=12)$. The mice were randomly divided into a control group $\left(\mathrm{ddH}_{2} \mathrm{O}, \mathrm{n}=6\right)$ and a treatment group $(2.45 \mathrm{~g} / \mathrm{kg}$ of Maytenus compound, $\mathrm{n}=6)$. The dose $(2.45 \mathrm{~g} / \mathrm{kg})$ was determined based on the results of the toxicological experiment by Puer Traditional Ethnomedicine Institute (Puer, China). The drug dose $(2.45 \mathrm{~g} / \mathrm{kg})$ refers to the dose of Maytenus compound tablets. The mice in the control group and treatment group were given $\mathrm{ddH}_{2} \mathrm{O}$ and Maytenus compound, respectively, intragastrically once per day. During the 30-day study period, tumor volume and body weight were measured every two days using a slide caliper and electronic scale. Tumor volume $\left(\mathrm{mm}^{3}\right)$ was calculated as follows: volume $=\left(\mathrm{D} \times \mathrm{d}^{2}\right) / 2$, where $\mathrm{D}$ is the longest diameter and $\mathrm{d}$ is the shortest diameter. To label the cells in the DNA synthesis phase (S phase), BrdU $(30 \mathrm{mg} / \mathrm{kg})$ was intraperitoneally injected into the mice $3 \mathrm{~h}$ before the mice were sacrificed. Tumors, liver, spleen and kidney were collected and weighed after the mice were sacrificed by cervical dislocation. Viscera index was calculated as follows: Viscera index $=t / T \times 100 \%$, where $t$ is the organ weight and $\mathrm{T}$ is the animal weight. Subcutaneous tumors extracted from mice in the control group and the drug treatment group were pooled based on group. In addition, protein was extracted for Western blot analysis.

To construct a liver orthotopic transplantation tumor model, HepG2 cells $\left(6 \times 10^{6}\right.$ cells $)$ mixed with Matrigel (Cat. No. 365234, BD) were subcutaneously injected into the liver of nude mice $(n=20)$. Then, the mice were randomly divided into a control group $\left(\mathrm{ddH}_{2} \mathrm{O}\right)$ and a treatment group $(2.45 \mathrm{~g} / \mathrm{kg}$ of Maytenus compound). One week after liver orthotopic transplantation, Maytenus compound treatment was started. The mice in the control group and treatment group were given $\mathrm{ddH}_{2} \mathrm{O}$ and Maytenus compound, respectively, intragastrically once per day for 30 days. The liver was collected and analyzed after the mice were sacrificed. All animal protocols were approved by the Committee on Ethics in Animal Experiments of Kunming Medical University. 


\section{Histological analysis and immunohisto- chemistry (IHC)}

Histological analysis and IHC were performed as described previously [14]. The primary antibody information is as follows: BrdU (GE Healthcare, dilution 1:50).

\section{Flow cytometry}

HepG2 cells were seeded in 6-well plates at $2 \times 10^{5}$ per well and cultured in complete medium in an incubator for $24 \mathrm{~h}$. Then, the cells were treated with various concentrations of Maytenus compound $(0,20$, 40 and $80 \mu \mathrm{g} / \mathrm{mL}$ ) for $24 \mathrm{~h}$. After treatment, the treated cells were harvested and washed with cold PBS buffer. The cells were resuspended in binding buffer and stained with $5 \mu \mathrm{L}$ of annexin V-FITC plus 5 $\mu \mathrm{L}$ of propidium iodide (Beyotime, Shanghai, China) for $0.5 \mathrm{~h}$ at $4{ }^{\circ} \mathrm{C}$ in the dark. The stained cells were washed with binding buffer three times to remove excess stain and then resuspended in $500 \mu \mathrm{L}$ of binding buffer. The percentage of apoptotic cells was analyzed using flow cytometry (BD, FACSCalibur, USA) within $1 \mathrm{~h}$. The experiment was repeated three times.

\section{Western blot analysis}

Protein lysates were separated on 10\% SDS-PAGE gels and electrophoretically transferred to PVDF membranes (Millipore, ISEQ00010). Then, the blots were probed with primary antibodies against EGFR (CST, \#4405), p-EGFR (CST, \#4407), PI3K (Abcam, ab189403), p-PI3K (Abcam, ab182651), AKT (Abcam, ab8932), p-AKT (Abcam, ab179463), FOXO3a (Abcam, ab109629), p-FOXO3a (Abcam, ab154786), p27 (Abcam, ab32034), p21 (Abcam, ab109502), and alpha tubulin (Abcam, ab52866) overnight at $4^{\circ} \mathrm{C}$, followed by incubation with an HRP-labeled horse anti-mouse IgG (CST, \#7076) or goat anti-rabbit IgG (CST, \#7074) for $1 \mathrm{~h}$ at room temperature. Signals were detected using enhanced chemiluminescence (ECL). Alpha tubulin was used as the protein loading control.

\section{Statistical analysis}

Statistical analysis was conducted using the SPSS 17.0 software package and GraphPad Prism 8.0 software. Two-tailed Student's t-test was used for comparisons of two independent groups. The chi-square test was used to analyze the association between the control group and Maytenus compound treatment group in the liver orthotopic transplantation tumor model. Values were deemed statistically significant at ${ }^{*} \mathrm{P}<0.05, \quad{ }^{* *} \mathrm{P}<0.01$ and $* * * \mathrm{P}<0.001$.

\section{Results}

\section{Maytenus compound inhibits the proliferation of HCC cells in vitro}

MTS cell proliferation, colony formation, and flow cytometry assays were performed to assess the inhibitory effect of different concentrations of Maytenus compound on the proliferation of HCC cells. The half maximal inhibitory concentration (IC50) values for Maytenus compound in HepG2 and BEL-7402 cells were $79.42 \pm 11.71 \mu \mathrm{g} / \mathrm{mL}$ and $78.48 \pm 8.87 \mu \mathrm{g} / \mathrm{mL}$, respectively (Figure 1A-B). HepG2 and BEL-7402 cells were treated with Maytenus compound at different concentrations $(0,20,40,80$ and $160 \mu \mathrm{g} / \mathrm{mL}$ ) in vitro based on the IC50 values. The results of the MTS cell proliferation assay indicated that Maytenus compound significantly inhibited the proliferation of HepG2 and BEL-7402 cells in a dose-dependent manner (Figure 1C-D, $P<0.001$ ). Colony formation results indicated that different concentrations of Maytenus compound (0, 20, 40, 80, and $160 \mu \mathrm{g} / \mathrm{mL}$ ) significantly inhibited the colony formation of HepG2 and BEL-7402 cells in a concentration-dependent manner (Figure 2A-C, $P<0.01$ ). The results of flow cytometry experiment showed that Maytenus compound, at each of the different concentrations tested $(20,40$, and $80 \mu \mathrm{g} / \mathrm{mL})$, significantly inhibited the cell cycle progression of HepG2 cells from growth 1 phase (G1 phase) to synthesis phase (S phase), leading to cell cycle arrest in G1 phase. In addition, the higher the concentration of Maytenus compound was, the more significant the G1 arrest (Figure 2D-E, $P<0.05$ ). The above results suggest that Maytenus compound can inhibit the proliferation of HCC cells in vitro through the inhibition of G1-S phase cell cycle progression.

\section{Maytenus compound inhibits the proliferation of HCC cells in vivo}

Nude mice received a subcutaneous injection of HepG2 cells and were divided into two groups: mice in the control and drug intervention groups were given $2.45 \mathrm{~g} / \mathrm{kg} /$ day of $\mathrm{ddH}_{2} \mathrm{O}$ and Maytenus compound, respectively, intragastrically for 30 days. The dose of Maytenus compound for intragastric administration was selected based on the results of toxicological experiments conducted in animals during the early stage of drug development. Maytenus compound significantly inhibited tumor proliferation in the mouse subcutaneous HCC tumor model (Figure 3). During the experiment, the volume and growth rate of subcutaneous tumors in the drug intervention group were significantly lower than those in the control group (Figure $3 \mathrm{~A}-\mathrm{B}, P<0.001$ ). Tumor weight in the drug intervention group was 
significantly lower than that in the control group (Figure $3 \mathrm{C}, P<0.01$ ). The calculated tumor inhibition rate for Maytenus compound was 66.94\% [tumor inhibition rate $=($ tumor weight in control group-tumor weight in treatment group)/tumor weight in control group]. Hematoxylin and eosin (H\&E) staining of subcutaneous carcinoma tissue sections showed that compared with the tumor tissue of the control group, a large amount of necrosis was found in the tumor tissue of the treatment group (Figure 3D). The number of BrdU-positive cells in the subcutaneous tumors in mice in the drug treatment group was significantly lower than that in mice in the control group (Figure 3D). The above results suggest that Maytenus compound suppresses the proliferation of HCC cells in vivo by decreasing the ratio of cells in $S$ phase.

After establishing a liver orthotopic transplantation tumor model using HepG2 cells, mice were randomly divided into control and treatment groups. One week after liver orthotopic transplantation, $\mathrm{ddH}_{2} \mathrm{O} \quad(2.45 \mathrm{~g} / \mathrm{kg} /$ day $)$ and Maytenus compound $(2.45 \mathrm{~g} / \mathrm{kg} /$ day $)$ were intragastrically administered to mice in the control and treatment groups, respectively, once per day for 30 days. Tissues were collected and analyzed after 30 days of treatment. The results showed that among
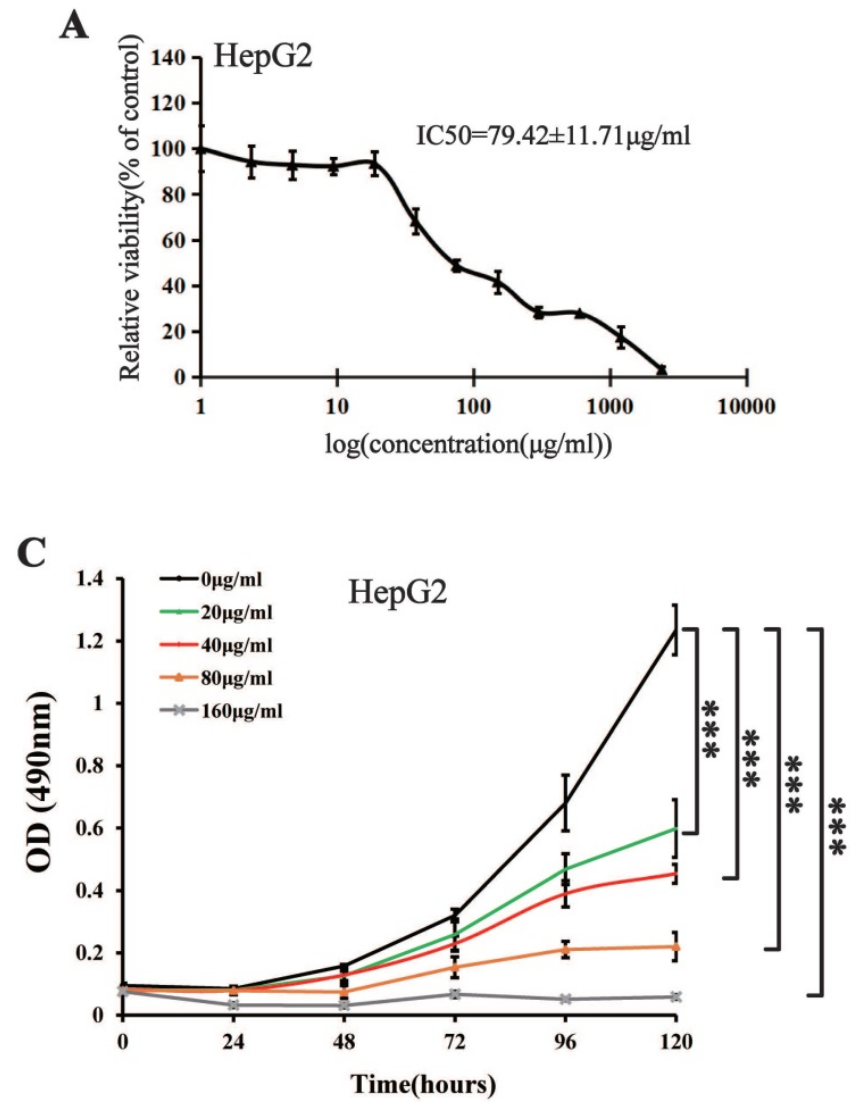

nude mice that received $\mathrm{ddH}_{2} \mathrm{O}, 90 \%$ exhibited tumor formation in the liver; in the treatment group, only $20 \%$ of nude mice exhibited tumor formation in the liver (Figure 3G-I). The difference between the two groups was significant $(P=0.005)$. The results suggest that Maytenus compound can inhibit the in situ proliferation of HCC cells in the liver.

\section{Preliminary evaluation of the safety of Maytenus compound}

In the course of intragastric administration, changes in the body weight of nude mice in the control and the treatment groups were measured and compared. The results showed that there was no significant difference in body weight between the two groups (Figure 3E). In addition, no statistically significant difference was observed in the vital organs (liver, spleen, and kidney) between the two groups (Figure 3F). These experimental results preliminarily demonstrate that Maytenus compound is safe and has no obvious organ toxicity.

\section{Maytenus compound promotes hepatoma cell apoptosis}

Flow cytometry results indicated that compared with the control group, different concentrations of Maytenus compound (20, 40, and $80 \mu \mathrm{g} / \mathrm{mL})$
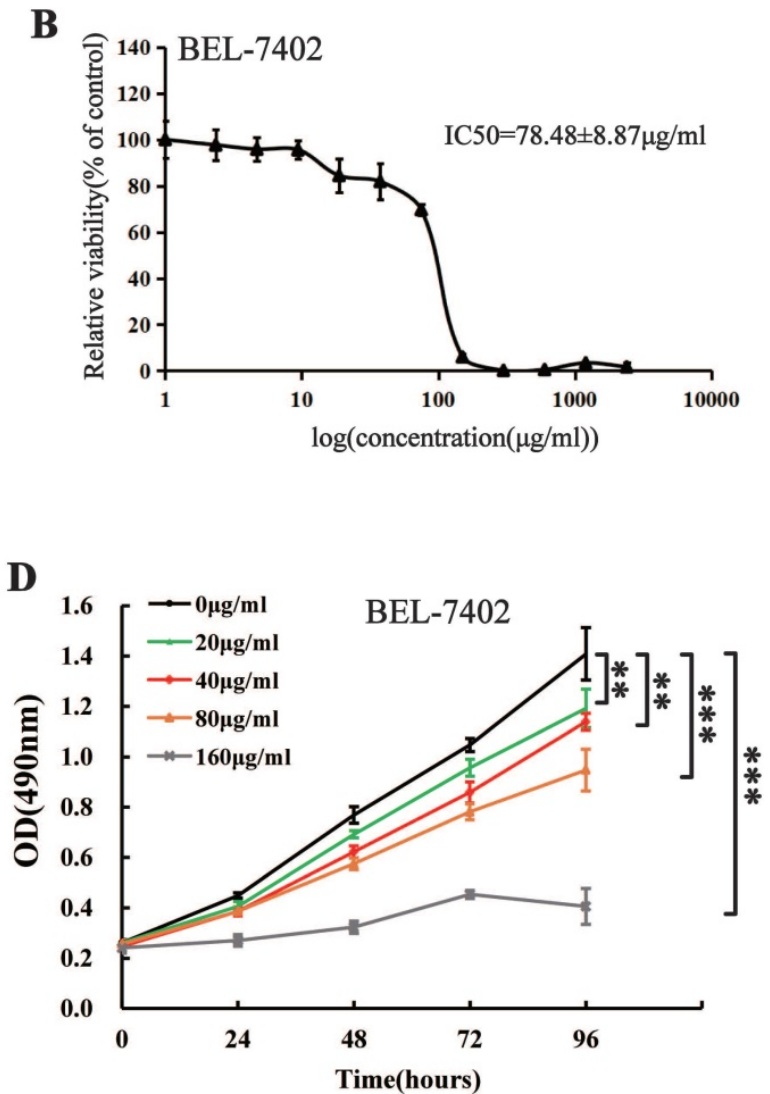

Figure 1. Effect of Maytenus compound on HepG2 and BEL-7402 cells in vitro. (A-B) IC50 of the Maytenus compound against HepG2 and BEL-7402 cells. (C-D) Cell proliferation of HepG2 and BEL-7402 cells treated with different concentrations of Maytenus compound was detected by MTS assay $(* * \mathrm{P}<0.01$, ***P $<0.001)$. 
significantly increased the number of cells in early apoptosis (Q4) and late apoptosis (Q2) (Figure 4A and $\mathrm{B}, \quad P<0.01)$. These results suggest that Maytenus compound can inhibit HCC cell proliferation by inducing cell apoptosis.

\section{Downregulation of the expression of key proteins in the EGFR-PI3K-AKT signaling pathway in vitro and in vivo by Maytenus compound}

Western blot results for subcutaneous tissue from the control and treatment groups showed that Maytenus compound significantly downregulated the expression of phosphorylated EGF receptor (p-EGFR), phosphorylated phosphatidylinositol 3 kinase (p-PI3K), and phospho-AKT (p-AKT) in nude mice, thereby upregulating the protein expression of phosphorylated forkhead box class $\mathrm{O} 3 \mathrm{a}$ (p-FOXO3a), cyclin dependent kinase inhibitor p27 (p27), and p21 (Figure 5A). The Western blot results for HCC cells treated with different concentrations of Maytenus compound showed that Maytenus compound downregulated the expression of key proteins in the EGFR-PI3K-AKT signaling pathway in vitro and that the downregulation amplitude was positively correlated with drug concentration (Figure 5B).

$\mathbf{A}$
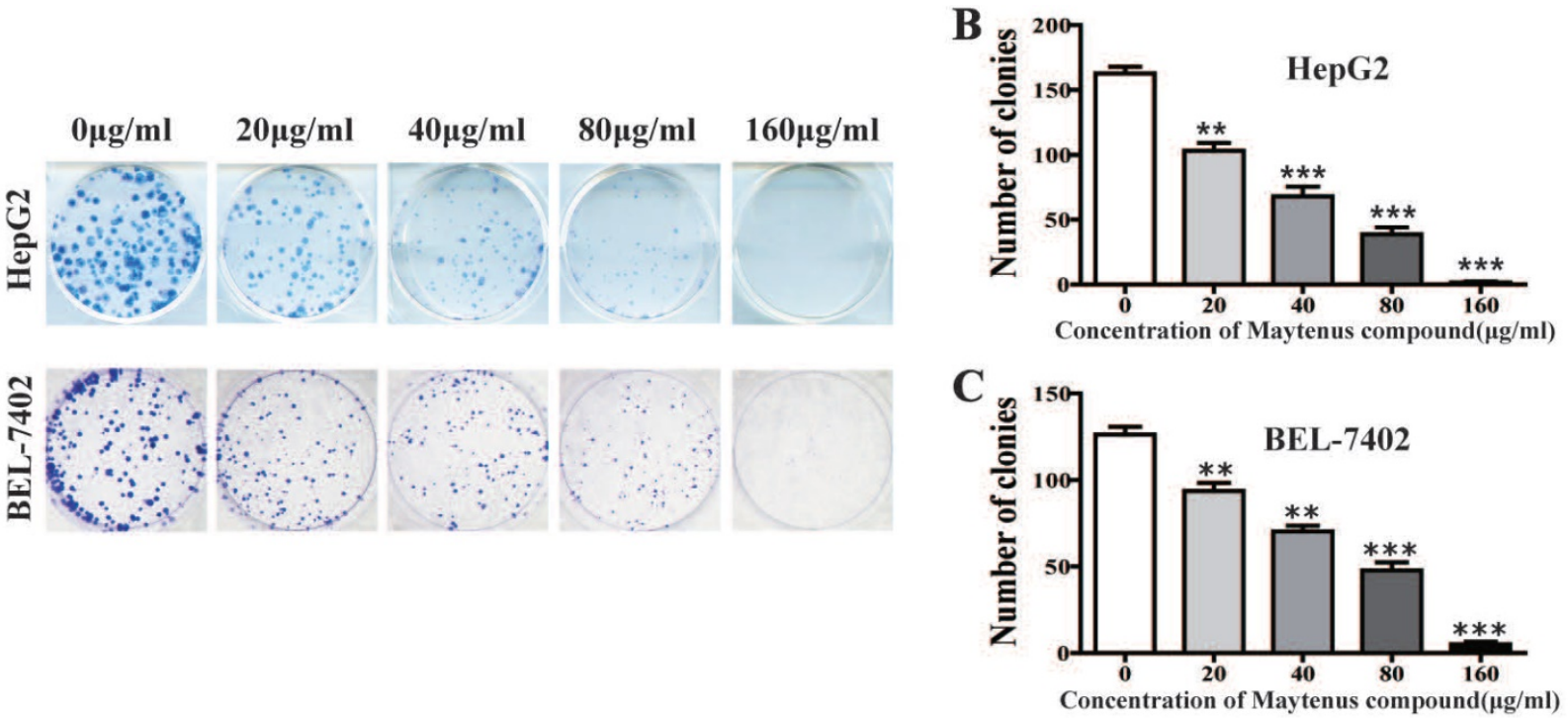

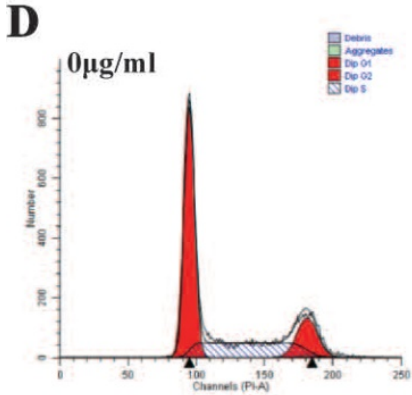

$\mathbf{E}$

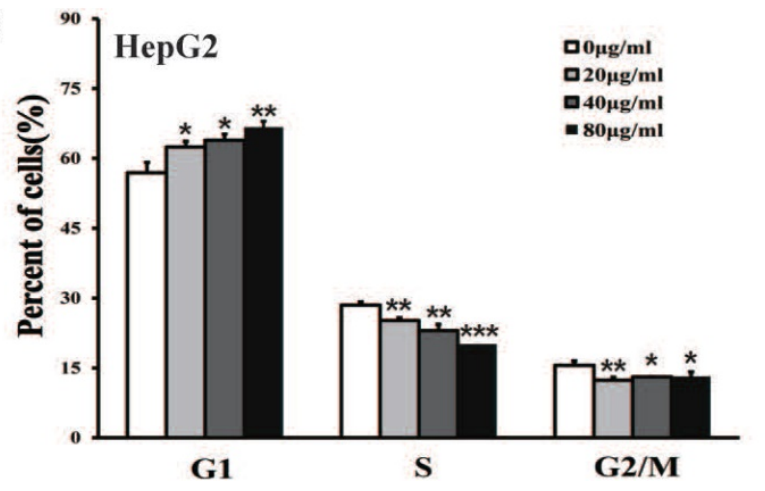

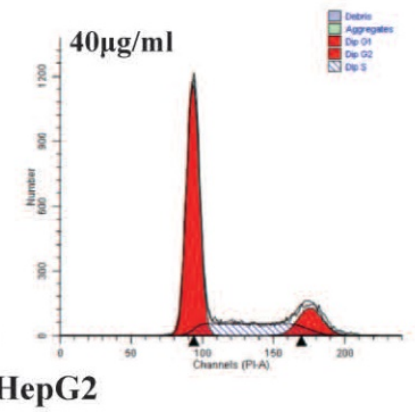

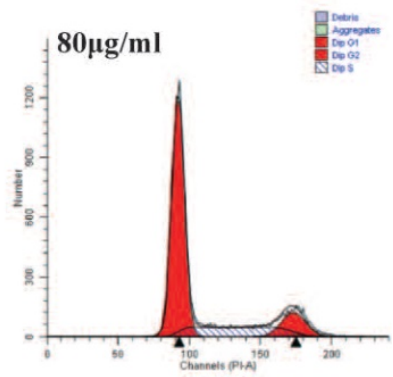

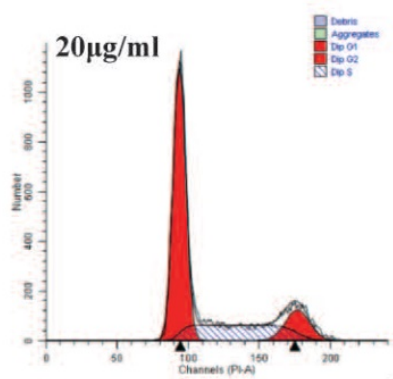

HepG2

\begin{tabular}{ccccc}
\hline & $0 \mu \mathrm{g} / \mathrm{ml}$ & $20 \mu \mathrm{g} / \mathrm{ml}$ & $40 \mu \mathrm{g} / \mathrm{ml}$ & $80 \mu \mathrm{g} / \mathrm{ml}$ \\
\hline G1(\%) & $56.87 \pm 2.26$ & $62.45 \pm 1.23$ & $63.88 \pm 1.33$ & $66.70 \pm 1.30$ \\
S(\%) & $28.50 \pm 0.70$ & $25.16 \pm 0.59$ & $23.00 \pm 1.37$ & $20.07 \pm 0.33$ \\
G2/M(\%) & $15.62 \pm 0.87$ & $12.39 \pm 0.64$ & $13.11 \pm 0.05$ & $13.23 \pm 0.97$ \\
\hline
\end{tabular}

Figure 2. Maytenus compound inhibits the proliferation of HCC cells in vitro. (A-C) Maytenus compound inhibited clone formation in HepG2 and BEL-7402 cells with a dose-dependent mode. (D-E) Maytenus compound inhibited cell cycle progression from G1 phase to $S$ phase in HepG2 cells with a dose-dependent mode $\left(* P<0.05\right.$, ${ }^{* * P}<0.01$, $* * * \mathrm{P}<0.001)$ 


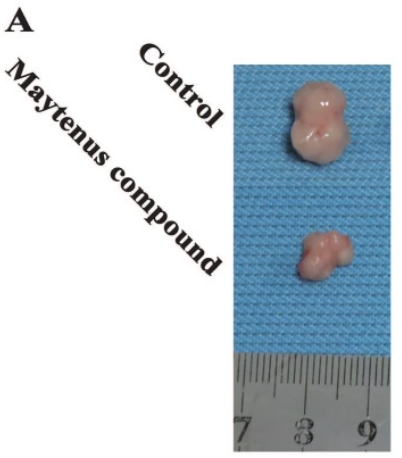

B

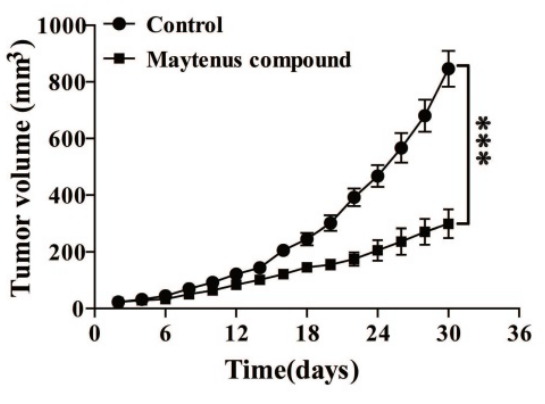

C

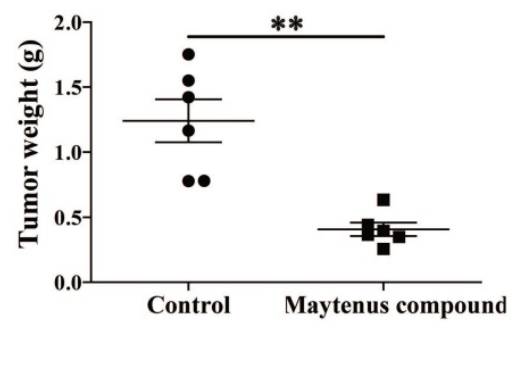

$\mathbf{E}$

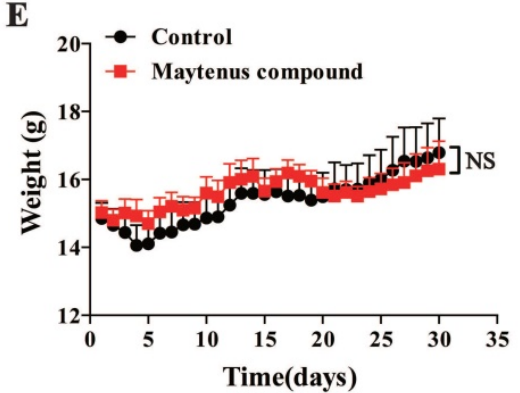

F

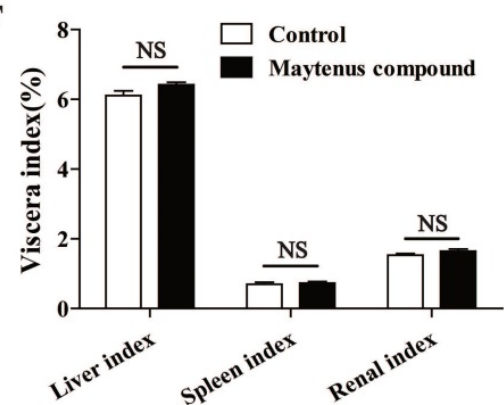

G

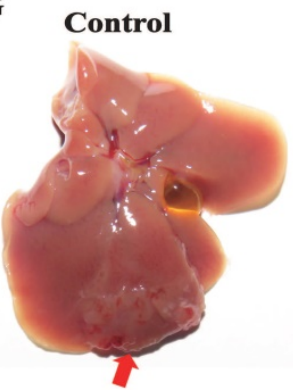

Maytenus compound

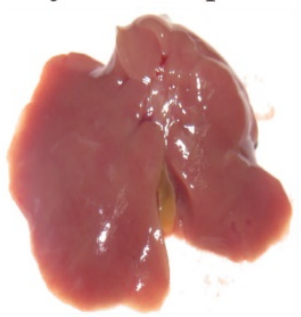

D
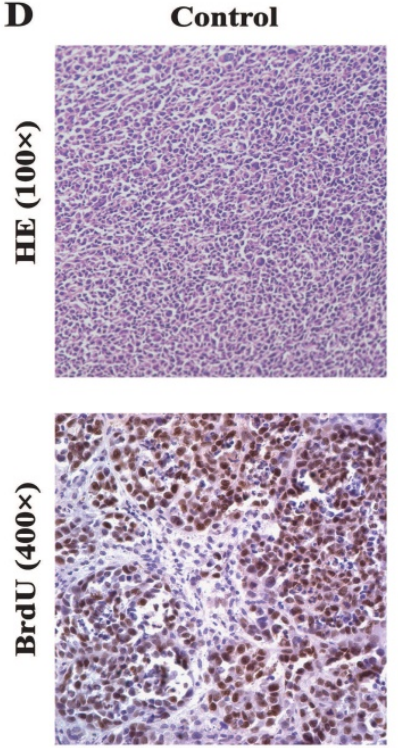

$\mathbf{H}$

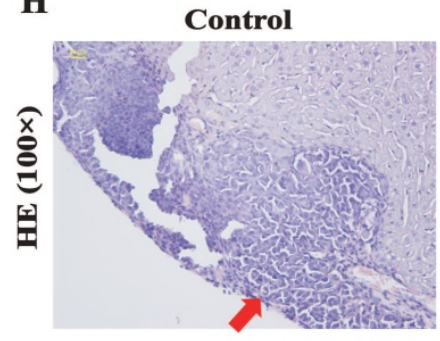

Maytenus compound
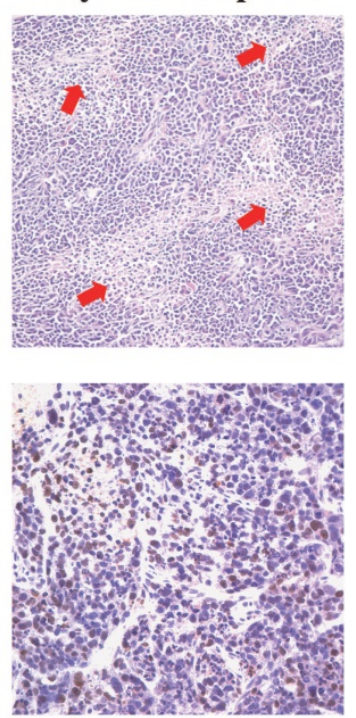

I

Liver orthotopic transplantation tumor model

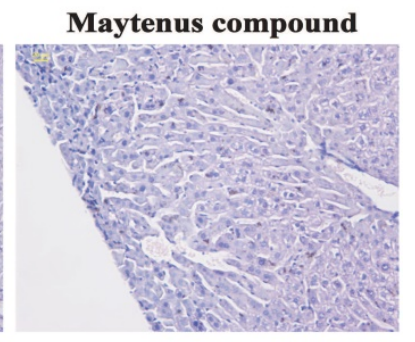

Figure 3. Maytenus compound inhibits HCC cell xenograft growth in nude mice. (A) Representative pictures of xenograft tumors treated with Maytenus compound and $\mathrm{dd} \mathrm{H}_{2} \mathrm{O}$, respectively ( $\mathrm{n}=6 /$ group). (B) Tumor growth curves of control group and Maytenus compound treatment group. (C) Tumor weight of control group and Maytenus compound treatment group. (D) Representative images of $\mathrm{HE}$ and BrdU staining of xenograft tumors of control group and Maytenus compound treatment group. The red arrow indicates cell necrosis. (E) The body weight of the nude mice in control group and Maytenus compound treatment group. (F) The viscera index of control group and Maytenus compound treatment group. (G) Representative pictures of liver orthotopic transplantation tumor treated with Maytenus compound and dd $\mathrm{H}_{2} \mathrm{O}$, respectively. $(\mathbf{H})$ Representative images of HE staining of liver orthotopic transplantation tumor of control group and Maytenus compound treatment group. The red arrow indicates the tumor formed in liver. (I) Liver tumor formation of the liver orthotopic transplantation tumor model after Maytenus compound treatment (**P $<0.01$, ***P $<0.001$ ). 


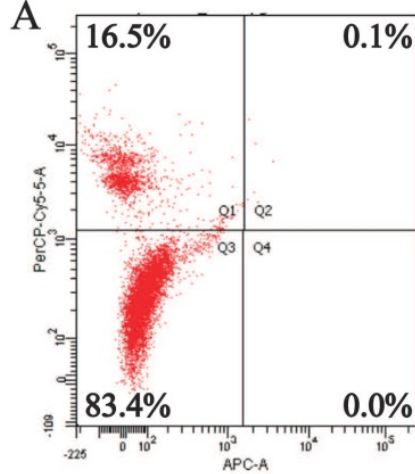

$0 \mu \mathrm{g} / \mathrm{ml}$

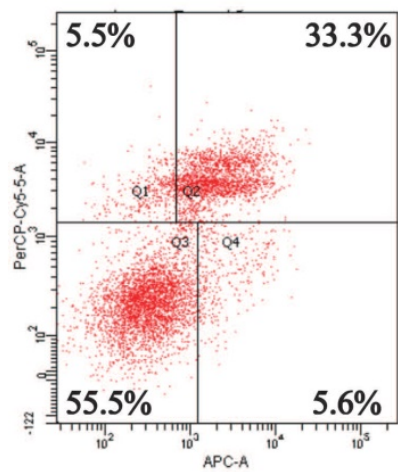

$40 \mu \mathrm{g} / \mathrm{ml}$

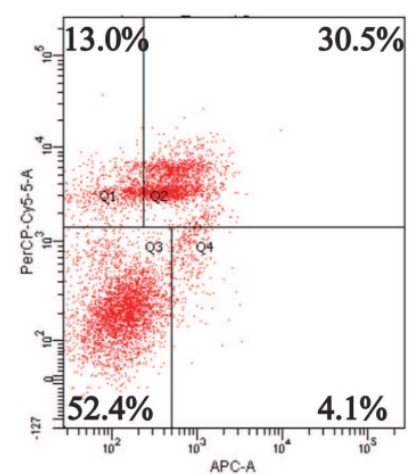

$20 \mu \mathrm{g} / \mathrm{ml}$

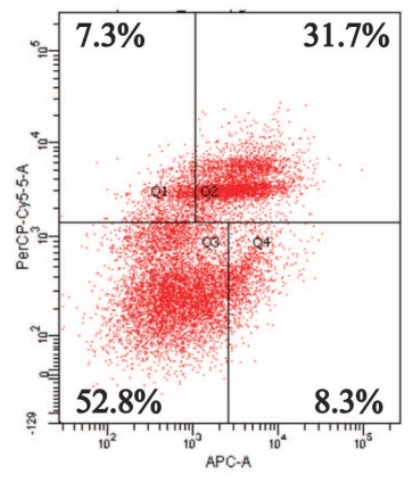

$80 \mu \mathrm{g} / \mathrm{ml}$
B

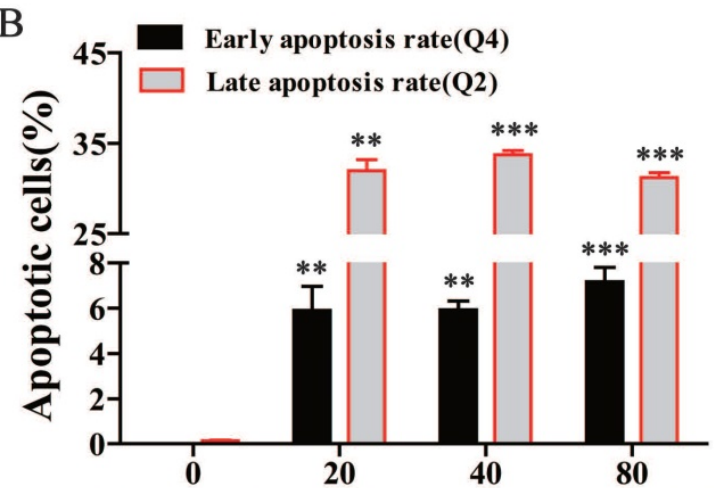

Concentration of Maytenus compound $(\mu \mathrm{g} / \mathrm{ml})$

Figure 4. Maytenus compound promotes apoptosis of HCC cells in vitro. (A) Apoptotic cell ratio was detected by flow cytometry. (B) Maytenus compound increased the early and late apoptotsis rate of $\mathrm{HepG} 2$ cells with a dose-dependent mode $(* * \mathrm{P}<0.01$, ***P $<0.001)$

\section{Discussion}

HCC is highly malignant, and HCC patients have a poor prognosis. There are limited treatment methods and drugs for HCC. Therefore, there is an urgent need for effective drugs. Traditional Chinese medicine has been used for cancer treatment for thousands of years, with a great accumulation of knowledge by the people who uses such treatment. With the development of traditional Chinese medicine, some Chinese herbal preparations or extracts, such as artemisinin, have been confirmed to have significant anticancer activity without obvious adverse side effects $[15,16]$. In this study, the Yunnan national medicine Maytenus compound also showed significant anti-HCC activity without significant organ toxicity.

Previous studies have shown that antitumor substances isolated from Maytenus compound developed in Yunnan are mainly maytansine and maytanprine [17]. Cell-based studies have shown that maytansine is nearly 100 -fold more cytotoxic than vinca alkaloids and exhibits highly potent antitumor activity [18]. Therefore, as early as the 1970s and 1980s, a great number of clinical studies attempted to apply maytansine to clinical treatments. Unfortunately, positive results for maytansine in the treatment of colorectal cancer [19] and melanoma [20], lymphoma [21], breast cancer [22], small cell lung cancer [23], soft tissue sarcoma [24], cervical cancer [25], and pancreatic cancer [26] were not obtained in phase II clinical studies primarily because maytansine has poor water solubility and high toxicity and is nonselective [18, 27], which led to extremely low dose-limiting toxicities $\left(2 \mathrm{mg} / \mathrm{m}^{2}\right)$ in the human body. Therefore, the manifestation of antitumor activity was not possible using a tolerable dose in humans [28]. The use of Maytenus as a traditional Chinese medicine preparation can reduce the dose-limiting toxicity of Maytenus folk prescriptions without reducing the efficacy of Maytenus compound preparations. This observation provides a new research idea for advancing the application of Maytenus compound, which contains maytansine and maytanprine, to clinical practice. Studies have shown that the efficacy of traditional Chinese medicine compound preparation results from the joint action of various ingredients of each medicine [29]. Maytenus compound is a Chinese herbal compound composed of six substances in accordance with the principle of monarch, minister, assistant and guide, and the inhibition of HCC proliferation results from the joint action of various ingredients.

The results at the cell level showed that the different drug concentrations of Maytenus compound significantly inhibited the proliferation of HCC cells in vitro and inhibited cell cycle progression from G1 to $S$ phase in HCC cells. In animal studies, BrdU was used to label cells at $S$ phase. Because BrdU is an analog of thymidine, BrdU can be incorporated into newly synthesized DNA when cells are in the DNA synthesis phase (S phase). Therefore, BrdU-positive cells are cells in $\mathrm{S}$ phase. Immunohistochemistry results showed that the number of BrdU-positive cells (cells in the $S$ phase) in the subcutaneous tumors in mice in the treatment group was significantly less than that in positive control cells from mice in the 

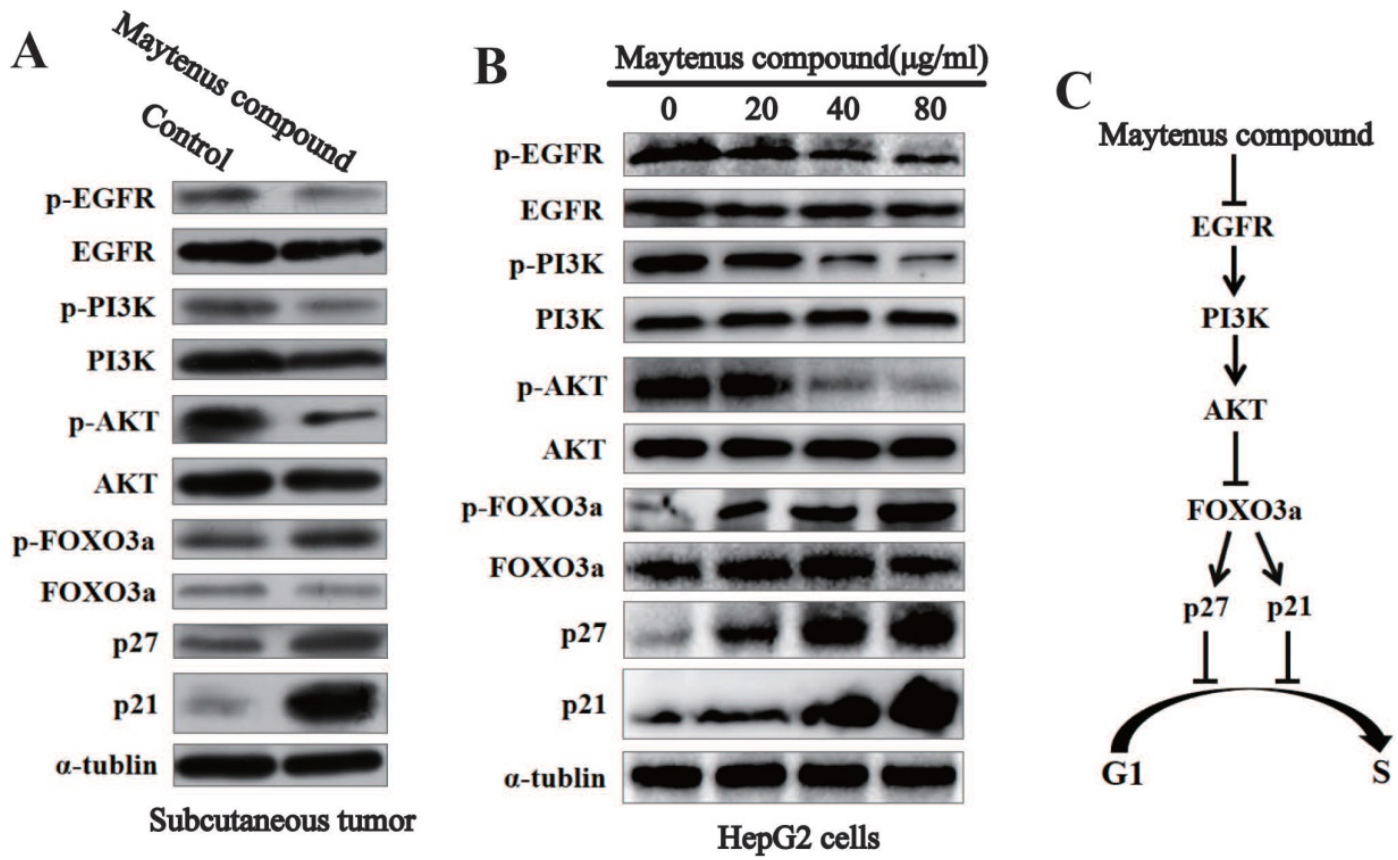

Figure 5. The EGFR-PI3K-AKT signaling pathway is down-regulated by Maytenus compound at the cell level in vitro and the animal level in vivo. (A) Maytenus compound suppresses EGFR-PI3K-AKT signaling pathway in subcutaneous tumor in nude mice. (B) Maytenus compound inhibits EGFR-PI3K-AKT signaling pathway in a dose-dependent manner in HepG2 cells. (C) A schematic diagram of the signal pathway that Maytenus compound inhibits HCC cell proliferation and induces cell cycle arrest via suppression of EGFR-PI3K-AKT pathway.

control group, indicating that Maytenus compound significantly inhibited cell cycle progression from G1 to $\mathrm{S}$ phase in HCC cells in vivo. The results from the cell experiments and animal studies are mutually reinforcing. To closely simulate the actual anti-HCC activity of Maytenus compound in vivo, we used a liver orthotopic transplantation tumor model in nude mice. Using this model, we confirmed that this drug inhibited the in situ proliferation of HCC cells in vivo. These results fully confirmed that Maytenus compound exhibits significant antiproliferative effects on HCC both in vitro and in vivo. More importantly, the drug used in this study is easy to produce and inexpensive and has been used for many years in clinical practice to treat mammary gland hyperplasia and uterine fibroids, confirming the good safety profile of this drug. These results strongly suggest that Maytenus compound can be a potential drug for the clinical treatment of HCC.

Epidermal growth factor receptor (EGFR) is a transmembrane tyrosine kinase receptor that can be activated by a variety of ligands and subsequently activate multiple signaling pathways that control proliferation, differentiation and survival [30], thereby promoting tumor cell proliferation, metastasis, and the inhibition of cell apoptosis [31]. Many studies have shown that the EGFR-PI3K-AKT signaling axis plays an important role in the malignant progression of HCC [31, 32]. Consistent with the above findings, Western blotting was used to detect changes in the protein levels of p-EGFR, EGFR,
p-PI3K, PI3K p-AKT, AKT, p-FOXO3a, FOXO3a, p27 and p21 in subcutaneous tumor tissue and HepG2 cells treated with Maytenus compound. The results showed that Maytenus compound downregulated the EGFR-PI3K-AKT signaling pathway at the cell culture level and in the animal model, further inhibiting cell cycle progression from G1 to S phase and thereby inhibiting HCC cell proliferation. Flow cytometry results showed that Maytenus compound induced HCC cell apoptosis. These results indicated that the anti-HCC effect of Maytenus compound was the result of the combined effects of the inhibition of proliferation and the promotion of apoptosis. The findings in this study that the expression of the EGFR-PI3K-AKT signaling pathway can be downregulated by Maytenus compound is also consistent with those of a previous study of Maytenus compound in lung cancer and cervical cancer cells [12].

We found that the Maytenus compound may inhibit HCC cell proliferation by downregulating the EGFR-PI3K-AKT signaling pathway, but its specific direct targets are unknown, requiring further studies. Studies have shown that many traditional Chinese medicines generate anticancer activities through multiple targets $[33,34]$. Therefore, there are other possible molecular mechanisms by which Maytenus compound inhibits HCC proliferation. In summary, this study confirms that Maytenus compound exhibits significant anti-HCC effects both in vitro and in vivo and revealed a possible mechanism of action, 
providing a theoretical basis for the clinical use of Maytenus compound as a therapeutic drug for HCC. However, the application of Maytenus compound in HCC patients must be further investigated through clinical trials.

\section{Acknowledgements}

This work was supported by the Applied Basic Research Foundation of Yunnan Province Science and Technology Department \& Kunming Medical University of China (Grant No. 2018FE001(-249), to W.T. Zhao; Grant No. 2018FE001(-243), to X.D. Xiang; Grant No. 2018FE001(-061), to Y. Zhang), the National Natural Science Foundation of China (Grant No. 82060425, to W.T. Zhao; Grant No. 81860485, to H.Y. Yang; Grant No. 82060504, to H.Y. Hu), the China Postdoctoral Science Foundation (Grant No. 2020M673595XB, to W.T. Zhao), the Basic Research Foundation of Yunnan Province Local Universities (Grant No. 202001BA070001-043, to L.X. Han; Grant No. 202001BA070001-063, to J.W. Xia).

\section{Competing Interests}

The authors have declared that no competing interest exists.

\section{References}

1. Luo P, Wu S, Yu Y, Ming X, Li S, Zuo X, et al. Current Status and Perspective Biomarkers in AFP Negative HCC: Towards Screening for and Diagnosing Hepatocellular Carcinoma at an Earlier Stage. Pathology oncology research : POR. 2020; 26: 599-603.

2. Liu X, Qin S. Immune Checkpoint Inhibitors in Hepatocellular Carcinoma: Opportunities and Challenges. The oncologist. 2019; 24: S3-s10.

3. Li L, Zhao GD, Shi Z, Qi LL, Zhou LY, Fu ZX. The Ras/Raf/MEK/ERK signaling pathway and its role in the occurrence and development of HCC. Oncology letters. 2016; 12: 3045-50.

4. Wang $\mathrm{H}, \mathrm{Lu} \mathrm{Z}$, Zhao $\mathrm{X}$. Tumorigenesis, diagnosis, and therapeutic potential of exosomes in liver cancer. 2019; 12: 133.

5. Ang C, O'Reilly EM, Abou-Alfa GK. Targeted agents and systemic therapy in hepatocellular carcinoma. Recent results in cancer research Fortschritte der Krebsforschung Progres dans les recherches sur le cancer. 2013; 190: 225-46.

6. Chan SL, Wong AM, Lee K, Wong N, Chan AK. Personalized therapy for hepatocellular carcinoma: Where are we now? Cancer treatment reviews. 2016; 45: 77-86.

7. Shao YY, Hsu CH, Cheng AL. Predictive biomarkers of sorafenib efficacy in advanced hepatocellular carcinoma: Are we getting there? World journal of gastroenterology. 2015; 21: 10336-47.

8. Reyes R, Wani NA, Ghoshal K, Jacob ST, Motiwala T. Sorafenib and 2-Deoxyglucose Synergistically Inhibit Proliferation of Both Sorafenib-Sensitive and -Resistant HCC Cells by Inhibiting ATP Production. Gene expression. 2017; 17: 129-40.

9. Finn RS, Ryoo BY, Merle P, Kudo M, Bouattour M, Lim HY, et al. Pembrolizumab As Second-Line Therapy in Patients With Advanced Hepatocellular Carcinoma in KEYNOTE-240: A Randomized, Double-Blind, Phase III Trial. Journal of clinical oncology : official journal of the American Society of Clinical Oncology. 2020; 38: 193-202.

10. Ni Y. Observation on the curative effect of Maytenus compound tablets in treating 30 cases of uterine fibroids. Chinese Journal of ethnomedicine and ethnopharmacy. 2013; 22: 134

11. Gong A, Yang S, Feng Z, Xu C, Yan H. Clinical Research on Maytenus Compound in the Treatment of Primary Hepatic Carcinoma. Journal of Chinese Medicine. 2014; 29: 1409-11.

12. Zeng B, Ge C, Zhao W, Fu K, Song X. Anticancer effect of the traditional Chinese medicine herb Maytenus compound via the EGFR/PI3K/AKT/ GSK3 $\beta$ pathway. Translational Cancer Research. 2019; 8: 2130-40.

13. Buck E, Eyzaguirre A, Brown E, Petti F, McCormack S, Haley JD, et al. Rapamycin synergizes with the epidermal growth factor receptor inhibitor erlotinib in non-small-cell lung, pancreatic, colon, and breast tumors. Molecular cancer therapeutics. 2006; 5: 2676-84.
14. Zhao WT, Lin XL, Liu Y, Han LX, Li J, Lin TY, et al. miR-26a promotes hepatocellular carcinoma invasion and metastasis by inhibiting PTEN and inhibits cell growth by repressing EZH2. Laboratory investigation; a journal of technical methods and pathology. 2019; 99: 1484-500.

15. Fan HN, Zhu MY, Peng SQ, Zhu JS, Zhang J, Qu GQ. Dihydroartemisinin inhibits the growth and invasion of gastric cancer cells by regulating cyclin D1-CDK4-Rb signaling. Pathology, research and practice. 2020; 216: 152795.

16. Chaib I, Cai X, Llige D, Santarpia M, Jantus-Lewintre E, Filipska M, et al. Osimertinib and dihydroartemisinin: a novel drug combination targeting head and neck squamous cell carcinoma. Annals of translational medicine. 2019; 7: 651.

17. Chen R, Hua Z, Lu Z, Wang J, Xu B. The efficacy of maytansine and maytanprine on animal tumors. Chinese Pharmaceutical Journal. 1982.

18. Tang X, Dai H, Zhu Y, Tian Y, Zhang R, Mei R, et al. Maytansine-loaded star-shaped folate-core PLA-TPGS nanoparticles enhancing anticancer activity. American journal of translational research. 2014; 6: 528-37.

19. O'Connell MJ, Shani A, Rubin J, Moertel CG. Phase II trial of maytansine in patients with advanced colorectal carcinoma. Cancer treatment reports. 1978; 62: $1237-8$.

20. Cabanillas F, Bodey GP, Burgess MA, Freireich EJ. Results of a phase II study of maytansine in patients with breast carcinoma and melanoma. Cancer treatment reports. 1979; 63: 507-9.

21. Rosenthal S, Harris DT, Horton J, Glick JH. Phase II study of maytansine in patients with advanced lymphomas: an Eastern Cooperative Oncology Group pilot study. Cancer treatment reports. 1980; 64: 1115-7.

22. Edmonson JH, Rubin J, Kvols LK, O'Connell MJ, Frytak S, Green SJ. Phase II study of maytansine in advanced breast cancer. Cancer treatment reports. 1981; 65: 536-7.

23. Creech RH, Stanley K, Vogl SE, Ettinger DS, Bonomi PD, Salazar O. Phase II study of cisplatin, maytansine, and chlorozotocin in small cell lung carcinoma (EST 2578). Cancer treatment reports. 1982; 66: 1417-9.

24. Borden EC, Ash A, Enterline HT, Rosenbaum C, Laucius JF, Paul AR, et al. Phase II evaluation of dibromodulcitol, ICRF-159, and maytansine for sarcomas. American journal of clinical oncology. 1982; 5: 417-20.

25. Thigpen JT, Ehrlich CE, Conroy J, Blessing JA. Phase II study of maytansine in the treatment of advanced or recurrent squamous cell carcinoma of the cervix. A Gynecologic Oncology Group study. American journal of clinical oncology. 1983; 6: 427-30.

26. Phase II trials of maytansine, low-dose chlorozotocin, and high-dose chlorozotocin as single agents against advanced measurable adenocarcinoma of the pancreas. Gastrointestinal Tumor Study Group. Cancer treatment reports. 1985; 69: 417-20.

27. Yu X, Wu H, Hu H, Dong Z, Dang Y, Qi Q, et al. Zein nanoparticles as nontoxic delivery system for maytansine in the treatment of non-small cell lung cancer. Drug delivery. 2020; 27: 100-9.

28. Chabner BA, Levine AS, Johnson BL, Young RC. Initial clinical trials of maytansine, an antitumor plant alkaloid. Cancer treatment reports. 1978; 62: 429-33.

29. Li C, Li P, Liu Y, Zhang S, Shi X, Xu T, et al. Research on Chemical Constituents and Compatibility of Chinese Compound Formula. Liaoning Journal of Traditional Chinese Medicine. 2014; 41: 2419-22.

30. Wu M, Zhang P. EGFR-mediated autophagy in tumourigenesis and therapeutic resistance. Cancer letters. 2020; 469: 207-16.

31. Zhangyuan G, Wang F, Zhang H, Jiang R, Tao X, Yu D, et al. Correction: VersicanV1 promotes proliferation and metastasis of hepatocellular carcinoma through the activation of EGFR-PI3K-AKT pathway. Oncogene. 2020; 39: 1388.

32. Zheng $H$, Yang $Y$, Hong YG, Wang MC, Yuan SX, Wang ZG, et al. Tropomodulin 3 modulates EGFR-PI3K-AKT signaling to drive hepatocellular carcinoma metastasis. Molecular carcinogenesis. 2019; 58: 1897-907.

33. Yang Z, Zhang Q, Yu L, Zhu J, Cao Y, Gao X. The signaling pathways and targets of traditional Chinese medicine and natural medicine in triple-negative breast cancer. Journal of ethnopharmacology. 2021; 264: 113249.

34. He R, Ou S, Chen S, Ding S. Network Pharmacology-Based Study on the Molecular Biological Mechanism of Action for Compound Kushen Injection in Anti-Cancer Effect. Medical science monitor: international medical journal of experimental and clinical research. 2020; 26: e918520. 